\title{
La importancia del pensamiento en la práctica médica
}

The importance of thought in medical practice

Ya desde hace varios siglos, los buenos médicos generaban aspectos relacionados al pensamiento, para lograr una mejor salud. Galeno, un gran maestro nacido en Grecia, luego estuvo en Roma, en una época donde ocurrían graves pandemias. Él trabajó como médico y filósofo, y habitualmente abordaba a los médicos para decirles que siempre mantuvieran la necesidad de pensar, ante las enfermedades.

Con el pasar del tiempo, ya en los años del siglo XVII, los médicos comenzaron a generar el pensamiento en grupos; y de esa forma se fue logrando algo de suma importancia en el cuidado de la salud. Era una oportunidad para que trabajasen juntos y generasen sus pensamientos, especialmente en la presencia de pacientes con trastornos difíciles y graves. Esto fue creciendo progresivamente para que pudieran resolver diversos problemas en la salud.

Desde los muchos cambios que ocurrieron en Medicina, en los años 1950 y posteriormente, cada vez más rápidos, lamentablemente, el pensamiento ya no era lo que solían efectuar los médicos desde aquellos años que han pasado. Actualmente, la gran mayoría actúan de otra forma, tal como atienden a los pacientes en unos pocos minutos, usan mucho las computadoras y abordan cada vez más la tecnología, que aumenta intensamente y sin frenar. Asimismo, están trabajando en presencia del mercantilismo, que ha ido apabullando a la medicina con factores inadecuados, y, por lo tanto, estamos contribuyendo a la pérdida de los valores éticos y morales de nuestra profesión.

El pensamiento es una acción sujeta a reglas, a menudo plagada de estereotipos sobre los que no se reflexionan, y suele no estar presente en nuestra conciencia. Es imprescindible que reflexionemos para que podamos conducirnos adecuadamente, ya que la conciencia del pensamiento es lo único que nos protege contra la insensatez y la frustración.

No obstante, el pensamiento médico se ha vuelto mucho más complejo, en especial por los cambios en el cuidado de los pacientes. Otros efectos, ocurren con las diferencias en los sistemas de la atención médica, y dejan de lado los conocimientos de la ciencia médica, $\mathrm{y}$, asimismo, no abordan el humanismo. La complejidad de la medicina, ahora puede exceder nuestras capacidades, $\mathrm{y}$, por lo tanto, deberíamos generar las acciones más adecuadas en el cuidado de los pacientes.

En este tiempo que estamos pasando, es frecuente ver que los médicos dicen que no tienen tiempo para pensar, en sus rutinas diarias. Esto es justamente lo que no deberían hacer, $\mathrm{y}$, asimismo, es el momento de la necesidad de pensar profundamente, y eso es más urgente que nunca, y los llevará a no tolerar la incertidumbre. Para evitar eso, es absolutamente necesario cultivar una actitud crítica, aprender notablemente las acciones que realizamos, y tener en cuenta que somos falibles en nuestros errores. Si los seguimos realizando en muchas acciones, serán cada vez más frecuentes, y de mayor riesgo. De ser así, la incertidumbre a menudo estará silenciada bajo el ropaje del profesionalismo, y otros recursos que llevan a que los médicos no tengan en cuenta la importancia de esta realidad.

La información, que puede ser inadecuada, hace imprescindible que probemos nuestras capacidades de pensar activamente, tal como lo realizan los buenos médicos. Ellos deben enseñar, principalmente a los de menor edad, tanto aquellos que están estudiando en las universidades, como los que ya están en la residencia. De no ocurrir así, hemos visto que muchos médicos jóvenes, solamente leen el resumen de los artículos. Siendo esto algo lamentable, deben saber que esas acciones no deben ocurrir en todo momento, ya que muchas veces son muy inadecuadas y peligrosas. Las decisiones médicas deberían generar diversas acciones adecuadas, mediante el pensamiento $y$, asimismo, con la ayuda de colegas que tengan mayor conocimiento.

En la profesión médica, también están experimentando cambios sociales rápidos, junto con la importancia en los fundamentos científicos y tecnológicos de la práctica médica. A través de nuestras acciones, cada vez más debemos generar el pensamiento.

Todos los médicos deberían saber que el pensamiento es una acción sujeta a reglas, que están llenas de cortocircuitos automáticos, de estereotipos y, asimismo, la mayoría no reflexiona ante lo que les dicen los pacientes. La reflexión es lo que nos lleva al pensamiento, y debemos tener nuestra conciencia, acorde con la ética. 
En los próximos años, la ciencia seguirá acumulando nuevas acciones diferentes a las actuales, y, por lo tanto, sería adecuado que tuviéramos mejores médicos, mediante las condiciones y necesidades de los pacientes. Esto se podría lograr, si en las Escuelas de Medicina enseñaran los avances en el cuidado de la salud, y será necesario que los futuros médicos puedan generar los pensamientos apropiados en todas las actividades que deben realizar.

La habilidad cognitiva es propiamente única de los seres humanos, mediante la habilidad de tener el conocimiento. Para entender otras acciones que realizan los médicos, es importante que sepan cómo generar lo que se denomina el pensamiento narrativo. Hay muchos médicos que realizan el pensamiento narrativo, que fue el núcleo central del arte de la medicina hasta el siglo XIX. Sería de suma importancia, que nuevamente estuviera presente el pensamiento narrativo porque sería de mucho valor en la actividad médica.

Nosotros solemos abordar muchos desafíos relacionados a las acciones médicas muy complicadas, y, por lo tanto, es muy poco probable que las soluciones sean simples. Si se les pide a los médicos que piensen ante estas situaciones, suelen decir que trabajan intensamente, y realmente están trabajando inadecuadamente. Entre otros aspectos, no es sorprendente que tomemos muchas decisiones equivocadas, y entre otras acciones que realizamos, están presentes los errores de diagnóstico que, sin duda, van a aumentar marcadamente.
El Dr. Alberto Agrest, que fue un excelente médico, nos dejó muchas palabras que fueron sumamente notorias, como esta que nos presenta "Es probable que hoy las verdades cuantitativas estén ocultando falsedades cualitativas. La dificultad con los números es que generan una sensación de certeza; algo que la realidad médica no admite, y es imprescindible aprender a tolerar la incertidumbre. En la medicina, la certeza es un certificado de ignorancia o insensatez".

Finalmente, debemos ver que la medicina del siglo XXI requerirá cambios fundamentales, acerca de cómo consideramos el pensamiento, en la estructura de la educación médica, la investigación y el humanismo.

\section{José María Ceriani Cernadas Editor en Jefe}

http: / / dx.doi.org/10.5546/ aap.2021.74

Texto completo en inglés:

http: / / dx.doi.org/10.5546/ aap.2021.eng.74

Cómo citar: Ceriani Cernadas JM. La importancia del pensamiento en la práctica médica. Arch Argent Pediatr 2021;119(2):74-75.

\section{REFERENCIAS}

- Obermeyer Z, Lee TH. Lost in Thought - The Limits of the Human Mind and the Future of Medicine. $N$ Engl J Med. 2017; 377(13):1209-11.

- Naylor CD. The evolution of schools of thought in medicine: Healthy tensions. JAMA. 2020; 323(11):1035-6.

- DeLeón J. Enseñando a pensar a los Estudiantes de Medicina: El Pensamiento Narrativo, Mecanístico y Matemático. Actas Esp Psiquiatr. 2018; 46(4):133-45.

- Casino G. Pensamiento científico. Barcelona: IntraMed/ Fundación Esteve; 2018. 